Article

\title{
Complex Soliton Solutions to the Gilson-Pickering Model
}

\author{
Haci Mehmet Baskonus \\ Department of Mathematics and Science Education, Faculty of Education, Harran University, Sanliurfa 63190, \\ Turkey; hmbaskonus@gmail.com
}

Received: 23 December 2018; Accepted: 31 January 2019; Published: 1 February 2019

\begin{abstract}
In this paper, an analytical method based on the Bernoulli differential equation for extracting new complex soliton solutions to the Gilson-Pickering model is applied. A set of new complex soliton solutions to the Gilson-Pickering model are successfully constructed. In addition, 2D and 3D graphs and contour simulations to the complex soliton solutions are plotted with the help of computational programs. Finally, at the end of the manuscript a conclusion about new complex soliton solutions is given.
\end{abstract}

Keywords: Gilson-Pickering equation; Bernoulli sub-equation function method; complex solutions; contour surfaces

AMS Subject Classifications: 35D99; 34M99; 35Axx; 35Mxx

\section{Introduction}

In the last several decades, many scientists have focused on new findings to the nonlinear differential equation, such as travelling wave solutions, complex, trigonometric, Jacobi elliptic functions, and so on. More recently, some methods have been considered as powerful tools for finding new solutions to the new models. In this sense, Claire Gilson and Andrew Pickering have introduced a model, after named the Gilson-Pickering equation (GPE), in 1995 [1]. Many other properties of this model defined as

$$
u_{t}-\varepsilon u_{x x t}+2 k u_{x}-u u_{x x x}-\alpha u u_{x}-\beta u_{x} u_{x x}=0,
$$

where $\varepsilon, k, \alpha, \beta$ are real constants have been investigated [2]. They have investigated this model in Painleve analysis by giving travelling wave solutions. This model includes many other nonlinear models, such as the Camassa-Holm equation, the Fornberg-Whitham equation, and the Rosenau-Hyman equation [3,4]. A. Chen et al. have studied Bifurcation of travelling wave solutions for Equation (1) [5]. The invariance and multiplier approach to the GPE have been introduced by Ghodrat Ebadi et al. [6]. C. Li, S. Tang, W. Huang, and A. Chen have presented the solitary patterns and periodic solutions for the generalized GPE in 2009 under some conditions [7]. Considering the special values of the parameters in Equation (1) as $\varepsilon=1, \alpha=-1, k=0.5$ and $\beta=3$ the Fornberg-Whitham equation reads [8]. Considered as $\varepsilon=0, \alpha=1, k=0$ and $\beta=3$, then, Equation (1) turns into the Rosenau-Hyman equation [7]. If these parameters are taken as $\varepsilon=1, \alpha=-3$, and $\beta=2$, GPE reads as the Fuchssteiner-Fokas-Camassa-Holm equation for the parameters [7]. For $\beta=1$, some new types of exponential function solutions, by using the first integral method, have been presented [9]. A. Irshad et al. have employed the Tanh-Coth method to seek the solutions of Equation (1), and some hyperbolic and exponential function solutions have been introduced to the literature [9]. Some important nonlinear models including such properties have been presented [10-41]. 
This manuscript is composed of the following sections. In Section 2, we present the Bernoulli sub-equation function method (BSEFM) [42-46]. W.X. Ma et al. have presented the BSEFM in a detailed manner and used it to find explicit and exact solutions to a Kolmogorov-Petrovskii-Piskunov equation in [47]. Similarly, many different solutions, such as complex, Lump, and mixed Lump-soliton solutions to the various models such as generalized Hirota-Satsuma-Ito, BKP and (2+1)-dimensional Ito equations have been obtained in [48-50]. We apply BSEFM to the GPE to find new contour simulations along with new solutions in Section 3. In the last section of the paper, we present a comprehensive conclusion by mentioning new findings.

\section{General Properties of BSEFM}

The general steps of the BSEFM are given as follows:

Step 1. It can be considered that the following is a nonlinear partial differential equation:

$$
P\left(u_{x}, u_{x x}, u_{t t}, u u_{x}, \cdots\right)=0,
$$

and the travelling wave transformation is:

$$
u(x, t)=U(\xi), \xi=m x-n t,
$$

in which $m, n$ are real constants and non-zero, respectively. Substituting Equation (3) into Equation (2) yields a nonlinear ordinary differential equation (NODE) as follows:

$$
N\left(U, U^{\prime}, U^{\prime \prime}, \cdots\right)=0,
$$

where $U=U(\xi), U^{\prime}=\frac{d U}{d \xi}, U^{\prime \prime}=\frac{d^{2} U}{d \xi^{2}}$.

Step 2. Supposing the trial solution of Equation (4) is as following:

$$
U=\sum_{i=0}^{s} a_{i} F^{i}=a_{0}+a_{1} F+a_{2} F^{2}+\cdots+a_{s} F^{s},
$$

and

$$
F^{\prime}=b F+d F^{M},
$$

where $F=F(\xi)$ is the Bernoulli differential polynomial and also $b \neq 0, d \neq 0, M \in \mathbb{R}-\{0,1,2\}$. Putting Equation (5) along with Equation (6) into Equation (4) produces an equation of polynomial $\Omega(F)$ of $F$ as following:

$$
\Omega(F)=\rho_{r} F^{r}+\cdots+\rho_{1} F+\rho_{0}=0 .
$$

We can obtain a relationship between $s$ and $M$ under the rules of the balance principle.

Step 3. Setting the coefficients of $\Omega(F)$ to all be zero gives an algebraic system of equations:

$$
\rho_{i}=0, i=0, \cdots, r .
$$

Solving this system, we get the values of $a_{0}, \ldots, a_{s}$.

Step 4. When we solve Equation (6), we obtain the following two situations according to $b$ and $d$ :

$$
\begin{aligned}
& F(\xi)=\left[\frac{-d}{b}+\frac{E}{e^{b(M-1) \xi}}\right]^{\frac{1}{1-M}}, b \neq d, \\
& F(\xi)=\left[\frac{(E-1)+(E+1) \tanh \left(\frac{b(1-M) \xi}{2}\right)}{1-\tanh \left(\frac{b(1-M) \xi}{2}\right)}\right]^{\frac{1}{1-M}}, b=d, E \in \mathbb{R} .
\end{aligned}
$$


Substituting Equation (5) into Equation (4), we can find the polynomial of $F$. Considering all the coefficients of same power of $F$ to zero gives an algebraic system of equations. By solving this system via several computational programs, we can find some new values of parameters of $a_{0}, \ldots, a_{s}$. This process gives many solutions to the model considered. For a better understanding of the solutions obtained in this manner, we can draw 2D, 3D, and contour graphical simulations of solutions for suitable values of parameters.

\section{Application of the BSEFM}

In this section, BSEFM has been successfully applied to the GPE to find more and new complex soliton solutions.

Example 1. Taking the travelling wave transformation asu $(x, t)=U(\xi), \xi=m x-n$ t which $m, n$ are real constants and non-zero, respectively, we get the following NODE:

$$
2 \varepsilon n m^{2} U^{\prime \prime}-2 m^{3} U U^{\prime \prime}+m^{3}(1-\beta)\left(U^{\prime}\right)^{2}-\alpha m U^{2}+(4 k m-2 n) U=0,
$$

in here, $\varepsilon, n, m, \beta, \alpha, k$ are both real constants and non-zero. Between $U^{\prime \prime}$ and $U^{2}$, relationship between s and $M$ can be obtained as following:

$$
2 M=s+2 .
$$

Case 1: If we define $s=4$ and $M=3$ in Equation (11), we can write the following travelling wave solution:

$$
\begin{gathered}
U=a_{0}+a_{1} F+a_{2} F^{2}+a_{3} F^{3}+a_{4} F^{4}, \\
U^{\prime}=a_{1} b F+a_{1} d F^{3}+2 a_{2} b F^{2}+2 a_{2} d F^{4}+3 a_{2} b F^{3}++3 a_{3} d F^{5} \\
+4 a_{4} b F^{4}+4 a_{4} d F^{6}
\end{gathered}
$$

and

$$
\begin{aligned}
& U^{\prime \prime}=b^{2} F a_{1}+4 b d F^{3} a_{1}+3 d^{2} F^{5} a_{1}+4 b^{2} F^{2} a_{2}+12 b d F^{4} a_{2}++8 d^{2} F^{6} a_{2}+9 b^{2} F^{3} a_{3} \\
& +24 b d F^{5} a_{3}+15 d^{2} F^{7} a_{3}+16 b^{2} F^{4} a_{4}++40 b d F^{6} a_{4}+24 d^{2} F^{8} a_{4},
\end{aligned}
$$

where $a_{4} \neq 0, b \neq 0, d \neq 0$. Putting Equations (12)-(14) into Equation (10), a system of algebraic equations, including various powers of $F$, can be obtained. Solving this system by using various computer programs, such as Mathematica, Maple, and Matlap, gives new complex soliton solutions, as follows:

Case 1.1. For $b \neq d$, the following coefficients can be selected:

$$
\begin{aligned}
& \beta=-2, a_{0}=2 k \varepsilon, a_{1}=0, a_{3}=0, a_{4}=\frac{-a_{2}^{2}}{12 k \varepsilon}, b=-\frac{12 d k \varepsilon}{a_{2}}, n=\frac{5 i a_{2}}{48 d \varepsilon^{3 / 2}}, \\
& m=\frac{i a_{2}}{24 d k \varepsilon^{3 / 2}}, \alpha=-\frac{1}{2 \varepsilon} .
\end{aligned}
$$

If these are entered into the Equation (12), together with Equation (9), the following novel complex solutions are given:

$$
u_{1}(x, t)=\frac{288 c^{2} k^{3} \varepsilon^{3} e^{-\frac{i}{\sqrt{\varepsilon}}(5 k t-2 x)}+192 a_{2} c k^{2} \varepsilon^{2} e^{-\frac{i}{2 \sqrt{\varepsilon}}(5 k t-2 x)}+2 k \varepsilon a_{2}^{2}}{\left(12 c k \varepsilon e^{-\frac{i}{2 \sqrt{\varepsilon}}(5 k t-2 x)}+a_{2}\right)^{2}}
$$

here $c, k, \varepsilon, a_{2} \in \mathbb{R}-\{0\}$. Considering the suitable values of parameters in Equation (16), 2D, 3D, and contour surfaces can be plotted as follows (Figures 1-3): 

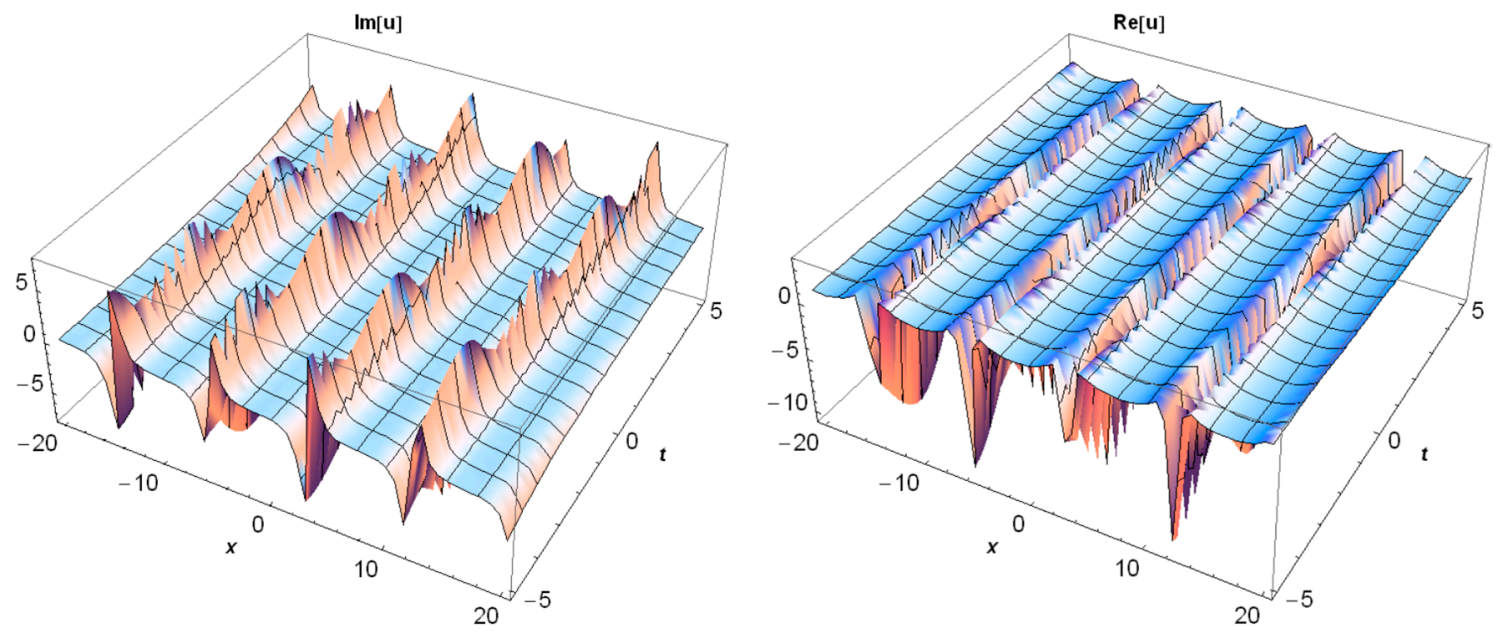

Figure 1. The three-dimensional graphs of Equation (16).
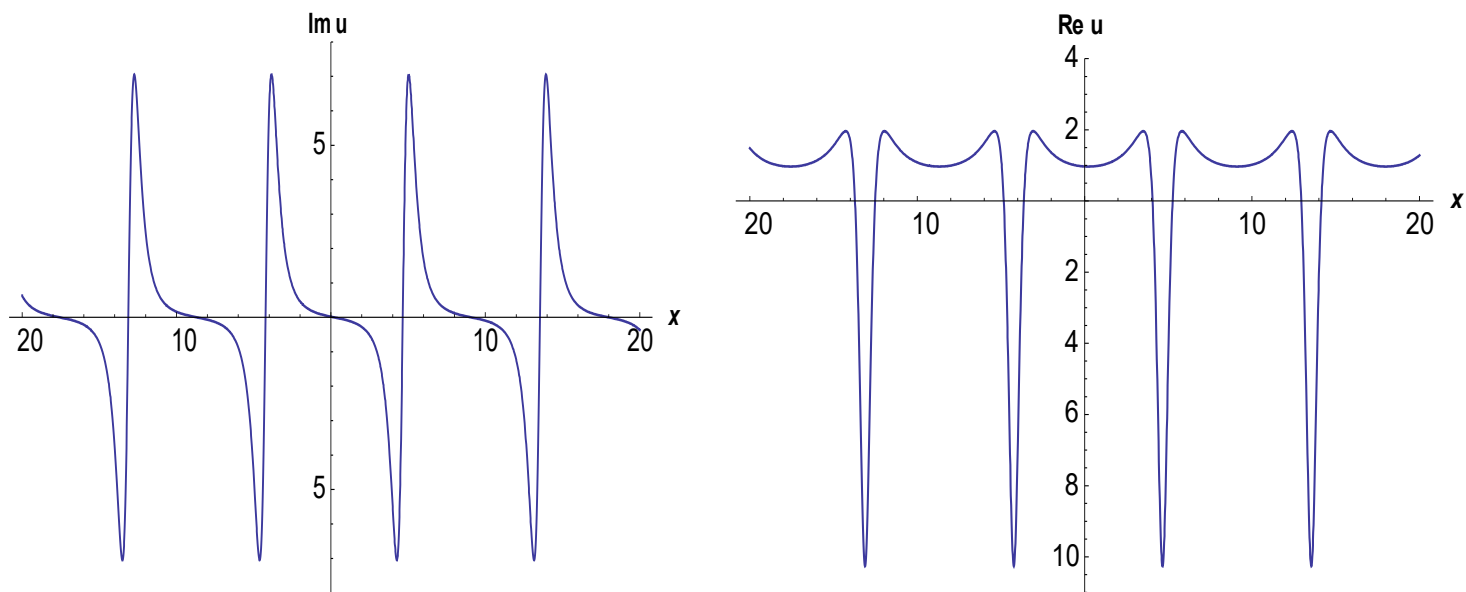

Figure 2. The two-dimensional graphs of Equation (16).
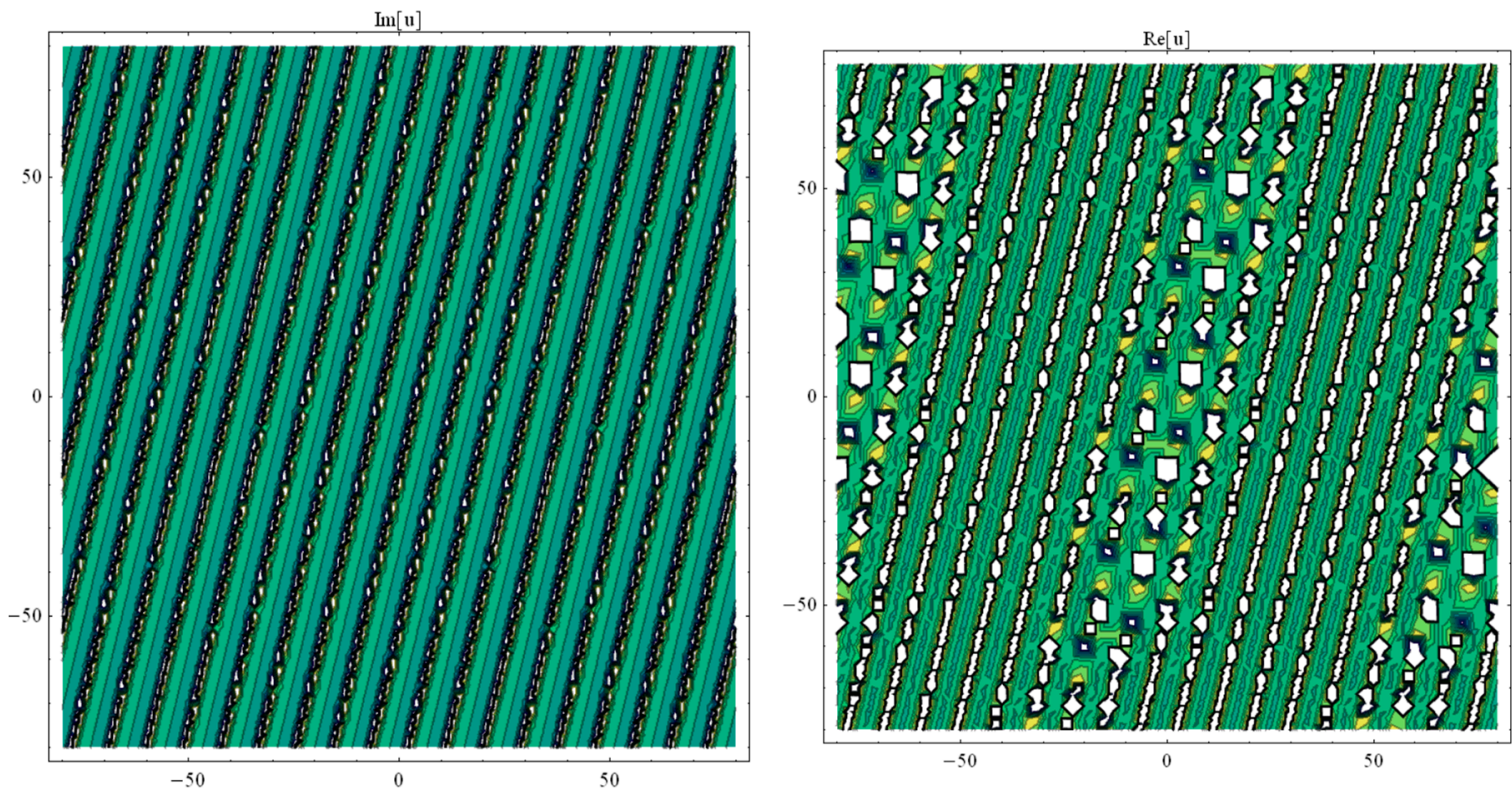

Figure 3. The contour simulations of Equation (16). 


\section{Case 1.2. When}

$$
\begin{aligned}
& \beta=-2, a_{1}=0, a_{3}=0, a_{0}=2 k \varepsilon, a_{4}=-2 i d m a_{2} \sqrt{\varepsilon}, b=\frac{i}{2 m \sqrt{\varepsilon}}, \\
& n=3 k m\left(1-\frac{8 i d k m \varepsilon^{3 / 2}}{a_{2}+24 i d k m \varepsilon^{3 / 2}}\right), \alpha=-\frac{a_{2}}{\varepsilon a_{2}+24 i d k m \varepsilon^{5 / 2}},
\end{aligned}
$$

this gives rise to another new complex soliton solution, as following solution:

$$
\begin{aligned}
u_{2}(x, t)= & 2 k \varepsilon+\frac{a_{2}}{c e^{-\frac{i}{m \sqrt{\varepsilon}}\left(m x-3 k m t\left(1-\frac{8 i d k m \varepsilon^{3 / 2}}{a_{2}+24 i d k m \varepsilon^{3 / 2}}\right)\right)}+2 i d m \sqrt{\varepsilon}} \\
& -2 i d m \sqrt{\varepsilon} a_{2}\left(c e^{-\frac{i}{m \sqrt{\varepsilon}}\left(m x-3 k m t\left(1-\frac{8 i d k m \varepsilon^{3 / 2}}{a_{2}+24 i d k m \varepsilon^{3 / 2}}\right)\right)}+2 i d m \sqrt{\varepsilon}\right)^{-2},
\end{aligned}
$$

where $c, k, \varepsilon, a_{2}, d, m$ are both real constants and non-zero. With suitable values of parameters entered into Equation (18), the following surfaces can be observed as (Figures 4-6):
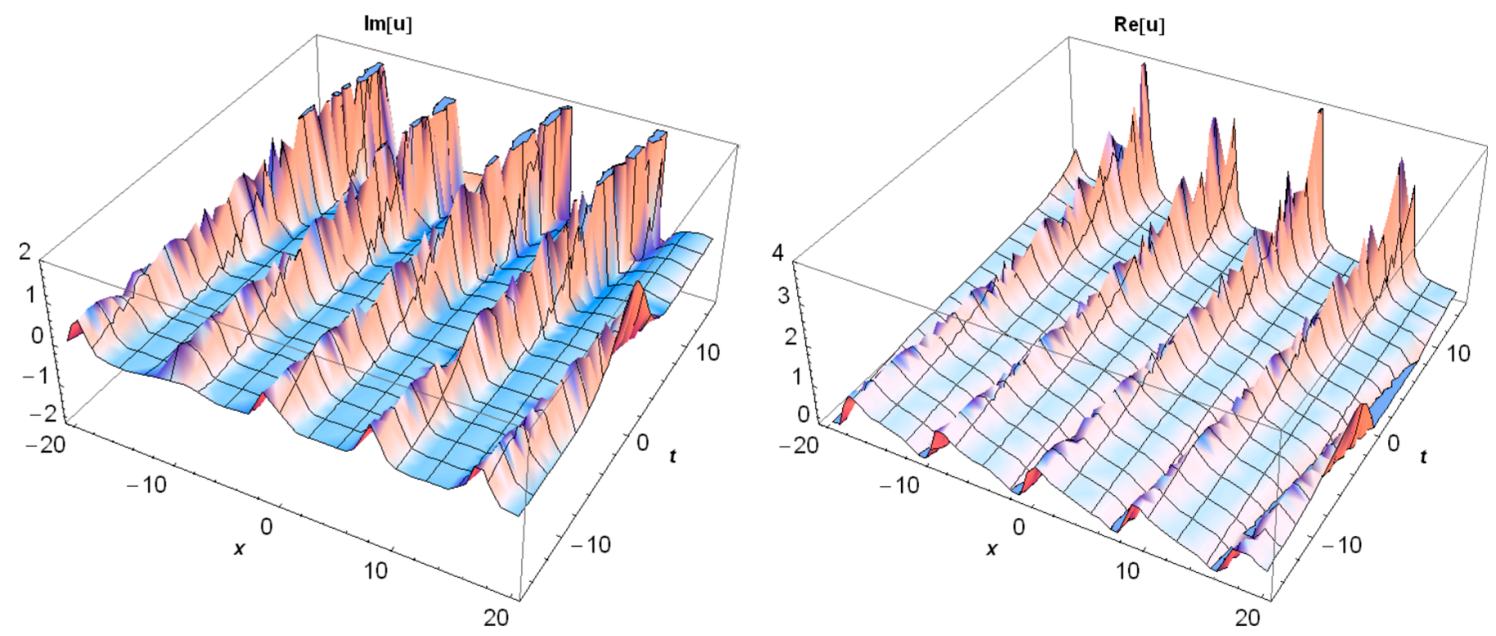

Figure 4. The three-dimensional graphs of Equation (18).
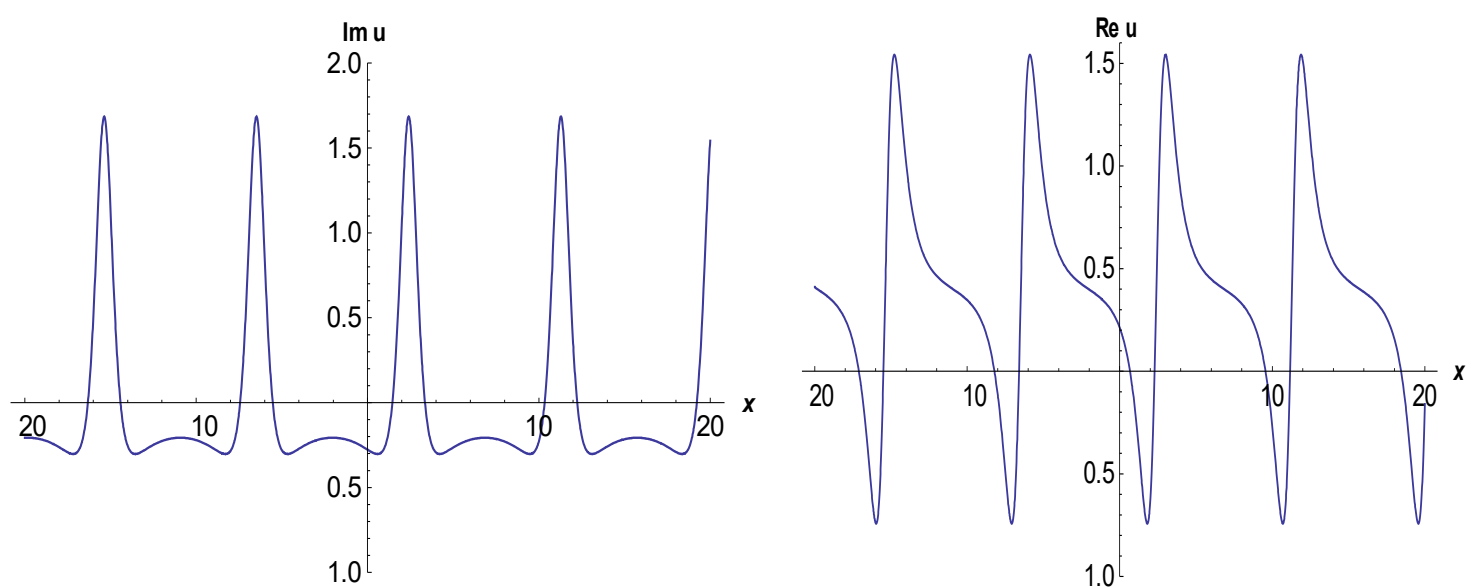

Figure 5. The two-dimensional graphs of Equation (18). 

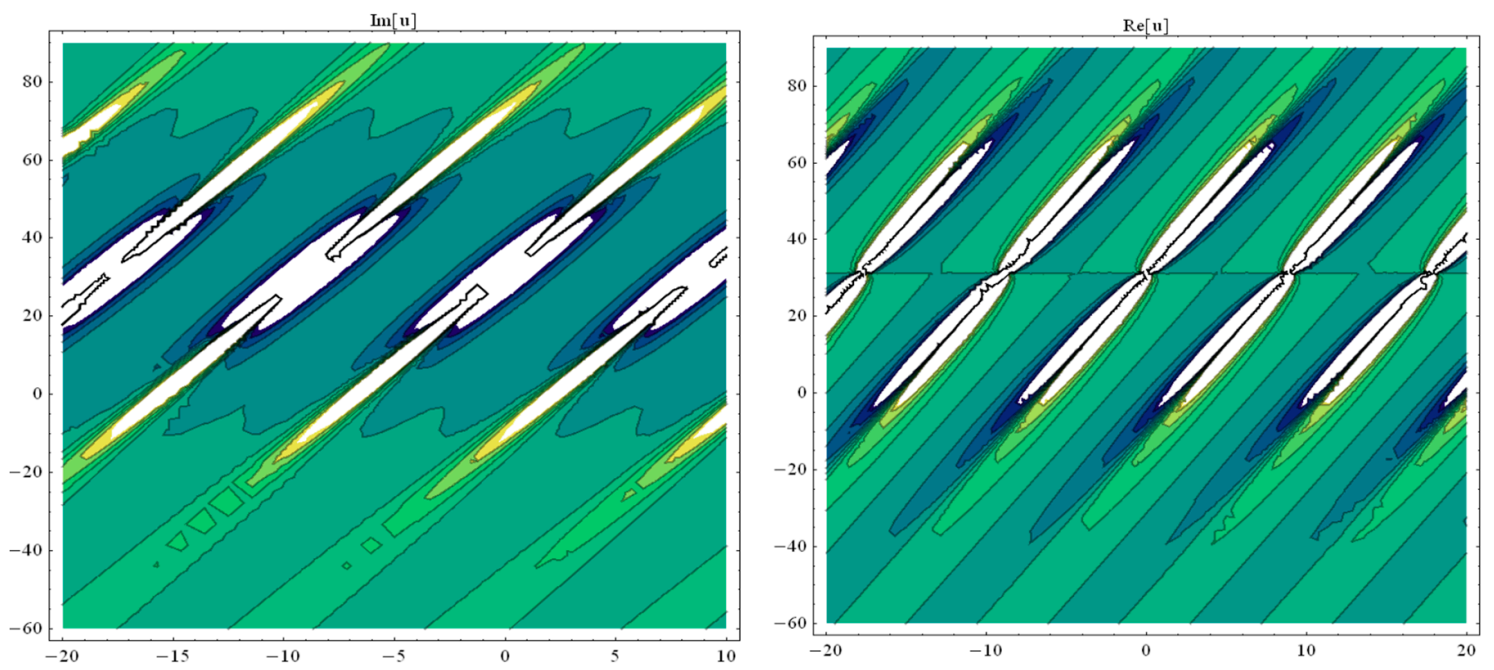

Figure 6. Contour simulations of Equation (18).

Case 1.3. For $b \neq d$, if

$$
\begin{aligned}
& \beta=-2, a_{1}=0, a_{3}=0, a_{0}=2 k \varepsilon, a_{4}=-\frac{a_{2}^{2}}{12 k \varepsilon}, b=-\frac{12 d k \varepsilon}{a_{2}}, \alpha=-\frac{1}{2 \varepsilon}, \\
& n=\frac{-5 i a_{2}}{48 d \varepsilon^{3 / 2}}, m=\frac{-i a_{2}}{24 d k \varepsilon^{3 / 2}},
\end{aligned}
$$

then these produce the following new complex soliton solution:

$$
u_{3}(x, t)=2 k \varepsilon-\frac{a_{2}^{2}}{12 k \varepsilon}\left(c e^{\frac{-i \kappa a_{2}}{24 k k^{3 / 2}} x+\frac{5 i \kappa a_{2}}{48 d \varepsilon^{3 / 2}} t}+\omega\right)^{-2}+a_{2}\left(c e^{\frac{5 i \kappa a_{2}}{48 d \varepsilon^{3 / 2}} t-\frac{i \kappa a_{2}}{24 d k \varepsilon^{3 / 2}} x}+\omega\right)^{-1},
$$

where $\kappa=\frac{24 d k \varepsilon}{a_{2}}, \omega=\frac{a_{2}}{12 k \varepsilon}$, and $k, \varepsilon, a_{2}, d, c$ are both real constants and non-zero. Considering the suitable values of parameters in Equation (20), the 2D, 3D, and contour surfaces can be observed as following (Figures 7-9):
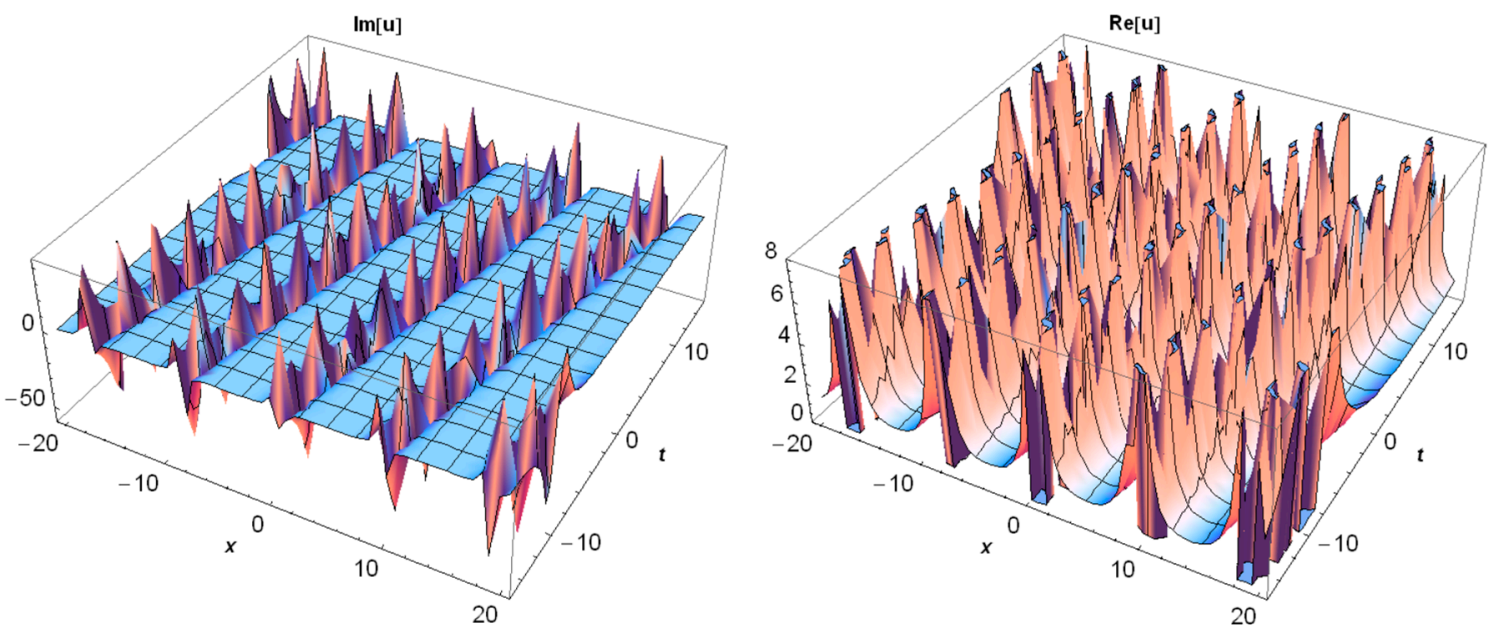

Figure 7. Three-dimensional graphs of Equation (20). 

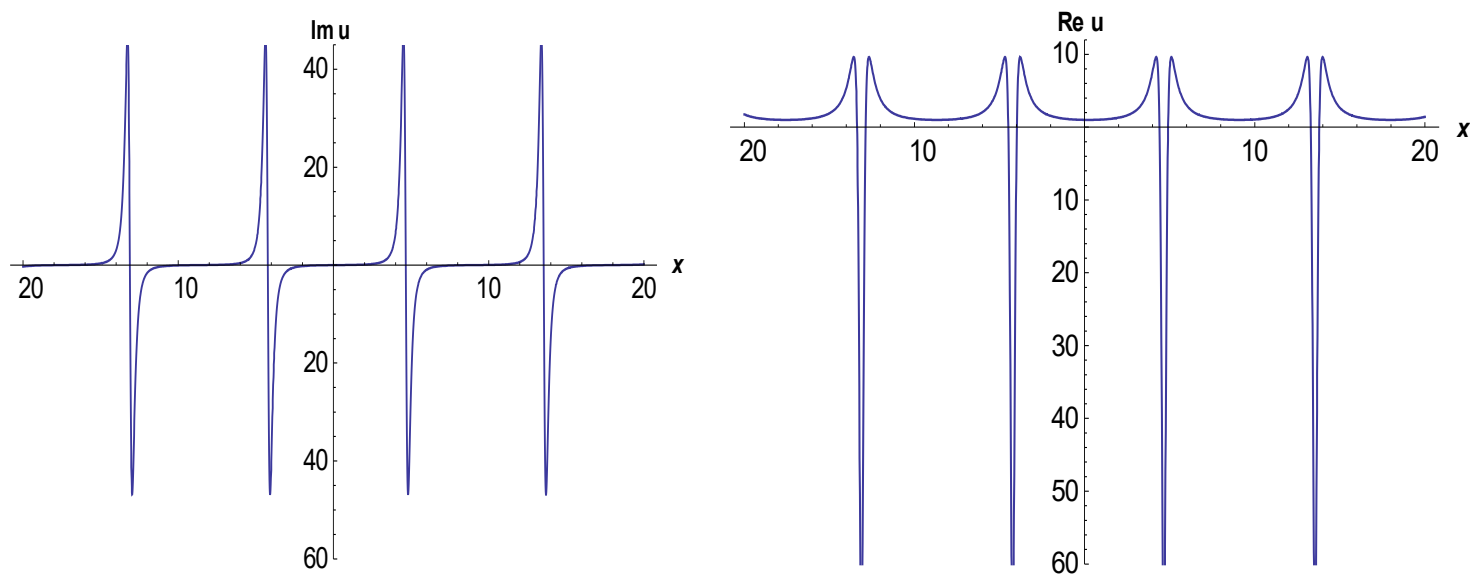

Figure 8. Two-dimensional graphs of Equation (20).
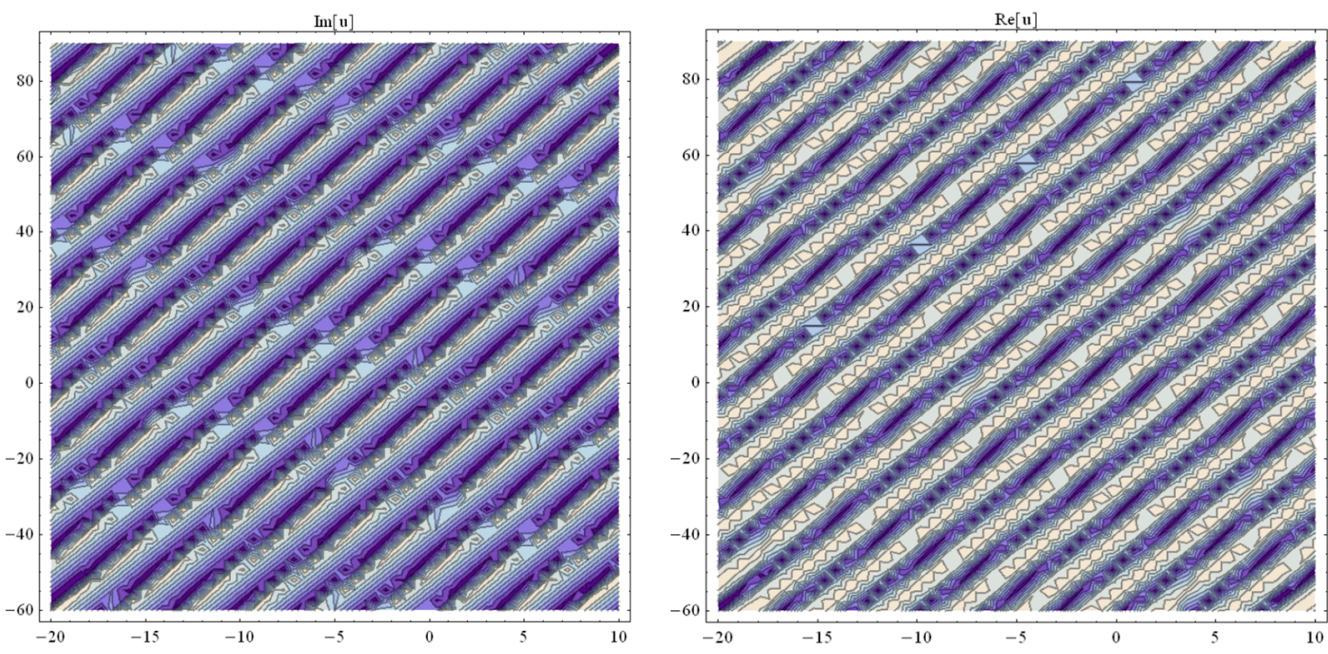

Figure 9. The contour simulations of Equation (20).

Case 1.4. Other coefficients for $b \neq d$ can be considered as follows:

$$
\begin{aligned}
& \beta=-2, a_{1}=0, a_{3}=0, a_{0}=2 k \varepsilon, a_{2}=\frac{i a_{4}}{2 d m \sqrt{\varepsilon}}, b=\frac{i}{2 m \sqrt{\varepsilon}}, n=\frac{3 k m\left(32 d^{2} k m^{2} \varepsilon^{2}+a_{4}\right)}{48 d^{2} k m^{2} \varepsilon^{2}+a_{4}}, \\
& \alpha=-\frac{a_{4}}{48 d^{2} k m^{2} \varepsilon^{2}+\varepsilon a_{4}} .
\end{aligned}
$$

Taking these coefficients in Equation (12), together with Equations (9) and (21), the following new soliton solution to Equation (1) can be obtained:

$$
\begin{aligned}
u_{4}(x, t)= & 2 k \varepsilon+a_{4}\left(c e^{\frac{-i}{m \sqrt{\varepsilon}}\left(m x-\frac{3 k m}{48 d^{2} k m^{2} \varepsilon^{2}+a_{4}}\left(32 d^{2} k m^{2} \varepsilon^{2}+a_{4}\right) t\right)}+2 i d m \sqrt{\varepsilon}\right)^{-2} \\
& +\frac{i a_{4}}{2 d m \sqrt{\varepsilon}}\left(c e^{\frac{-i}{m \sqrt{\varepsilon}}\left(m x-\frac{3 k m}{48 d^{2} k m^{2} \varepsilon^{2}+a_{4}}\left(32 d^{2} k m^{2} \varepsilon^{2}+a_{4}\right) t\right)}+2 i d m \sqrt{\varepsilon}\right)^{-1},
\end{aligned}
$$

where $k, \varepsilon, a_{4}, c, m, d$ are both real constants and non-zero (Figures 10-12). 

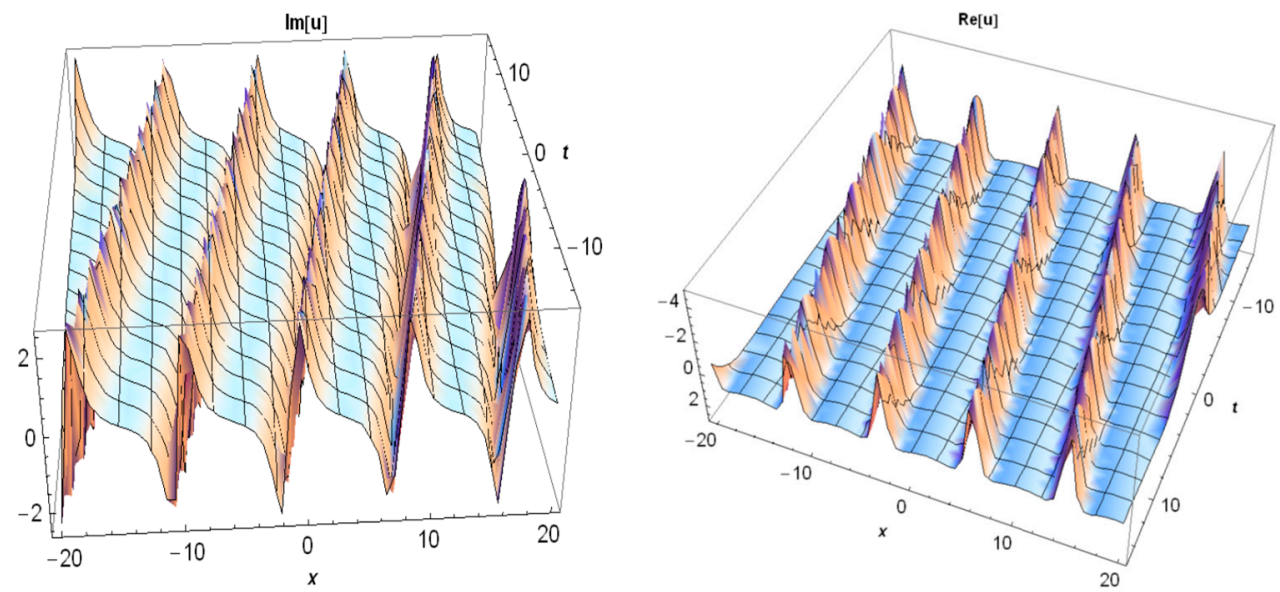

Figure 10. The 3D surfaces of Equation (22).
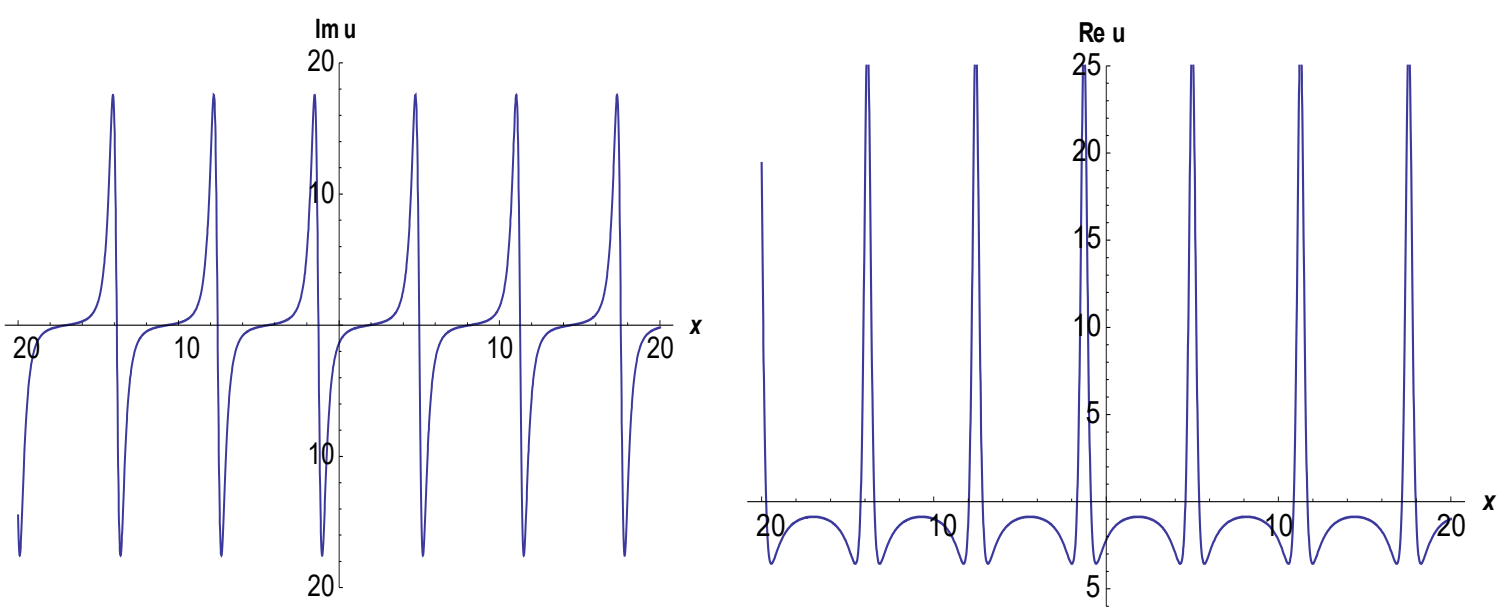

Figure 11. 2D surfaces of Equation (22).
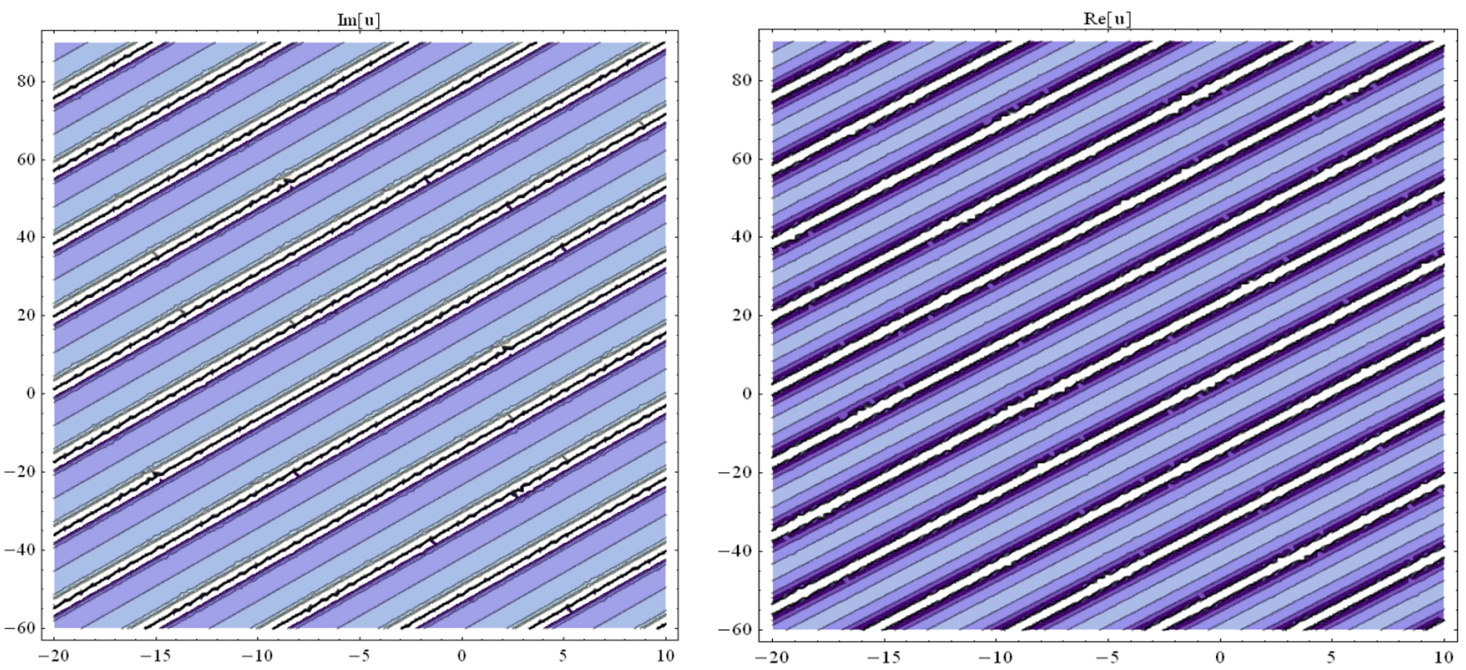

Figure 12. Contour simulations of Equation (22).

Case 2: Taking $s=6$ and $M=4$ in Equation (11), we can write the following travelling wave solution:

$$
U=a_{0}+a_{1} F+a_{2} F^{2}+a_{3} F^{3}+a_{4} F^{4}+a_{5} F^{5}+a_{6} F^{6},
$$




$$
U^{\prime}=a_{1} F^{\prime}+2 a_{2} F^{\prime} F+3 a_{3} F^{\prime} F^{2}+4 a_{4} F^{\prime} F^{3}+5 a_{5} F^{\prime} F^{4}+6 a_{6} F^{\prime} F^{5}
$$

where $a_{6} \neq 0, F^{\prime}=b F+d F^{4}, b \neq 0, d \neq 0$, When we put Equations (23) and (24) into Equation (10), we can find a system including various powers of $F$. Solving this system with the help of using different computer programs, such as Mathematica, Maple, and Matlap, gives the following coefficients and soliton solutions:

Case 2.1. For $b \neq d$, the following coefficients can be chosen as:

$$
\begin{aligned}
& \beta=-2, a_{0}=2 k \varepsilon, a_{1}=a_{2}=a_{4}=a_{5}=0, a_{6}=-3 i d m a_{3} \sqrt{\varepsilon}, b=\frac{i}{3 m \sqrt{\varepsilon}}, \\
& n=3 k m\left(1-\frac{12 i d k m \varepsilon^{3 / 2}}{36 i d k m \varepsilon^{3 / 2}+a_{3}}\right), \alpha=-\frac{a_{3}}{\varepsilon a_{3}+36 i d k m \varepsilon^{5 / 2}} .
\end{aligned}
$$

Considering Equation (25) along with Equation (9) into Equation (23) produces another novel complex soliton solution:

$$
u_{5}(x, t)=2 k \varepsilon+\frac{a_{3}}{c e^{\frac{-i}{\sqrt{\varepsilon}}(x-3 k t+i \omega t)}+3 i d m \sqrt{\varepsilon}}-\frac{3 i d m \sqrt{\varepsilon} a_{3}}{\left(c e^{\frac{-i}{\sqrt{\varepsilon}}(x-3 k t+i \omega t)}+3 i d m \sqrt{\varepsilon}\right)^{2}}
$$

where $\omega=\frac{36 d k^{2} m \varepsilon^{3 / 2}}{36 i d k m \varepsilon^{3 / 2}+a_{3}}$ and $k, \varepsilon, a_{3}, c, d, m$ are both real constants and non-zero. With suitable values of parameters in Equation (26), 2D, 3D, and contour surfaces can be seen as (Figures 13-15):
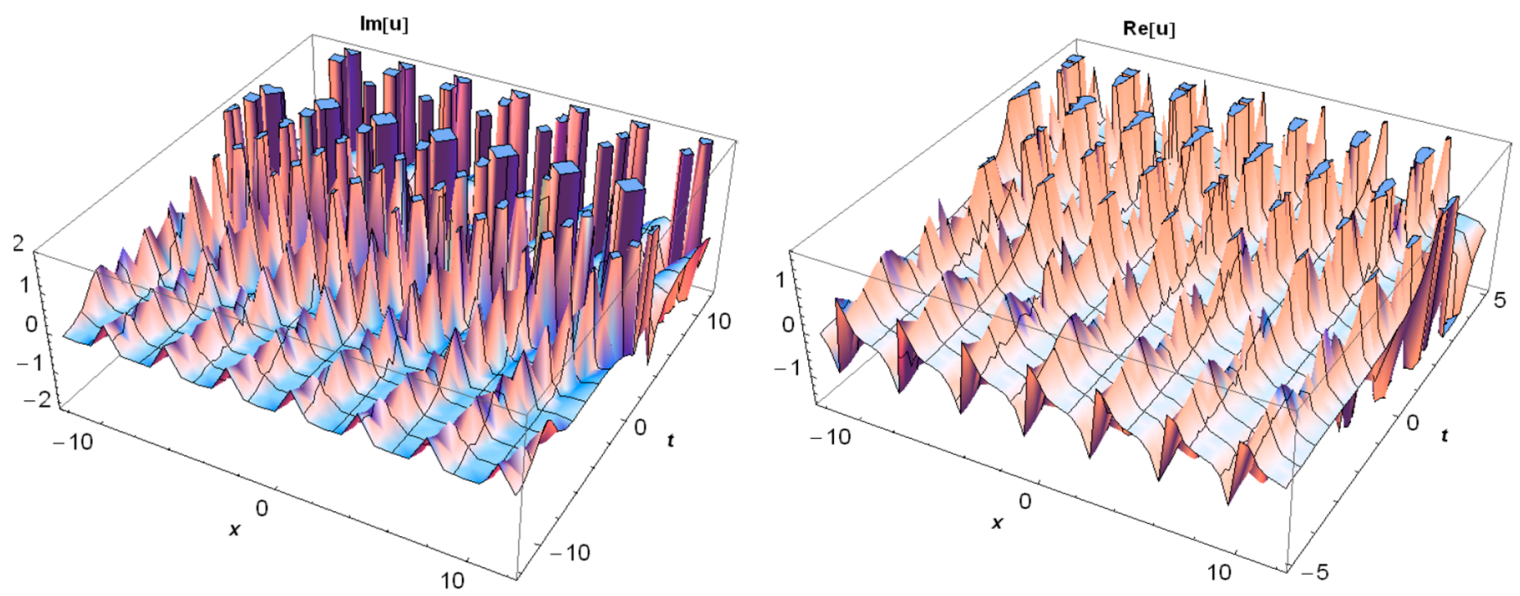

Figure 13. 3D surfaces of Equation (26).
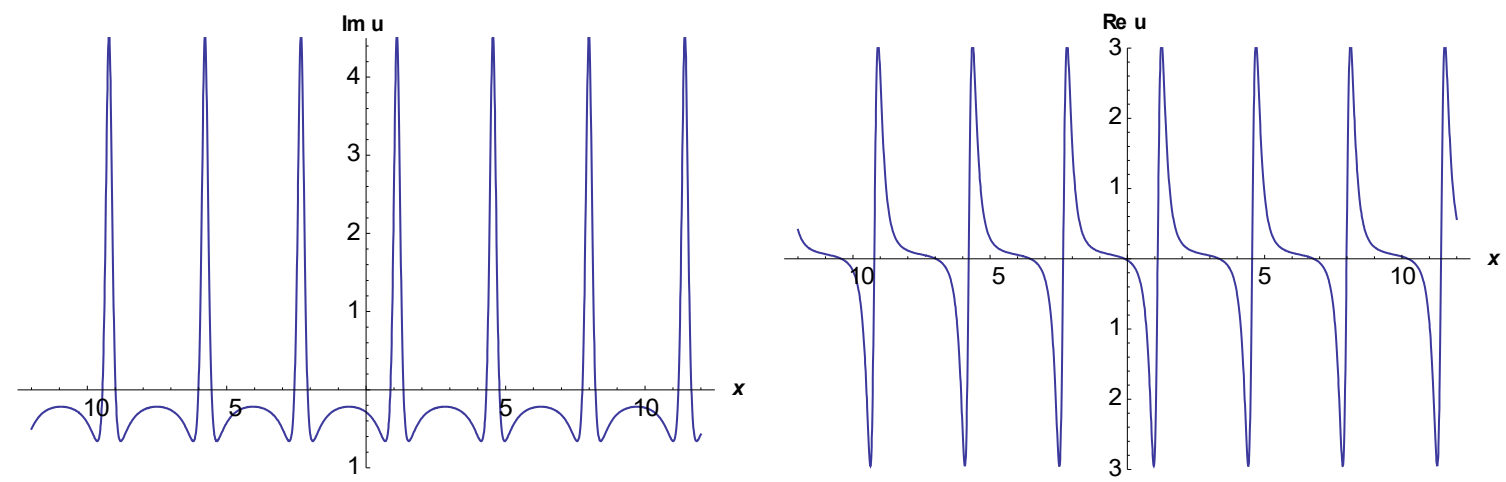

Figure 14. 3D surfaces of Equation (26). 

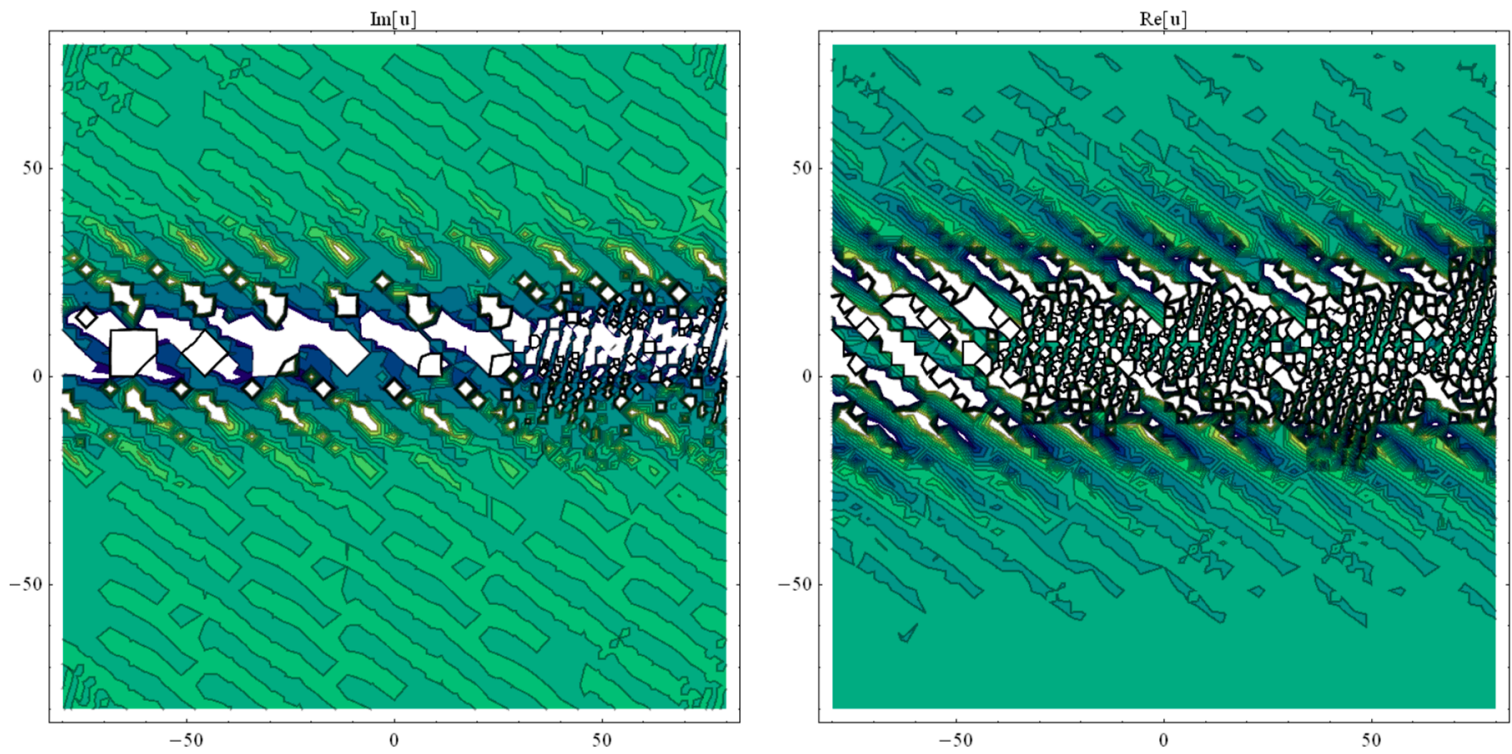

Figure 15. Contour simulations of Equation (26).

Case 2.2. Other coefficients for Equation (1) and for $b \neq d$ can be considered as follows:

$$
\begin{aligned}
& \beta=-2, a_{0}=2 k \varepsilon, a_{1}=a_{2}=a_{4}=a_{5}=0, a_{6}=\frac{d a_{3}}{b}, n=\frac{i k\left(-8 d k \varepsilon+b a_{3}\right)}{b \sqrt{\varepsilon}\left(-12 d k \varepsilon+b a_{3}\right)}, \\
& m=\frac{i}{3 b \sqrt{\varepsilon}}, \alpha=\frac{b a_{3}}{12 d k \varepsilon^{2}-b \varepsilon a_{3}} .
\end{aligned}
$$

Regulating Equation (23) under the terms of Equations (9) and (27), another new complex solution for Equation (1) can be found as following:

$$
u_{6}(x, t)=2 k \varepsilon+\frac{d a_{3}}{b\left(-\frac{d}{b}+c e^{\frac{-i x}{\sqrt{\varepsilon}}+\frac{3 i k t\left(-8 d k \varepsilon+b a_{3}\right)}{\sqrt{\varepsilon}\left(-12 d k \varepsilon+b a_{3}\right)}}\right)^{2}}+\frac{a_{3}}{-\frac{d}{b}+c e^{\frac{-i x}{\sqrt{\varepsilon}}+\frac{3 i k t\left(-8 d k \varepsilon+b a_{3}\right)}{\sqrt{\varepsilon}\left(-12 k k \varepsilon+b a_{3}\right)}}},
$$

in which $k, \varepsilon, b, d, c, a_{3}$ are both real constants and non-zero (Figures 16-18).
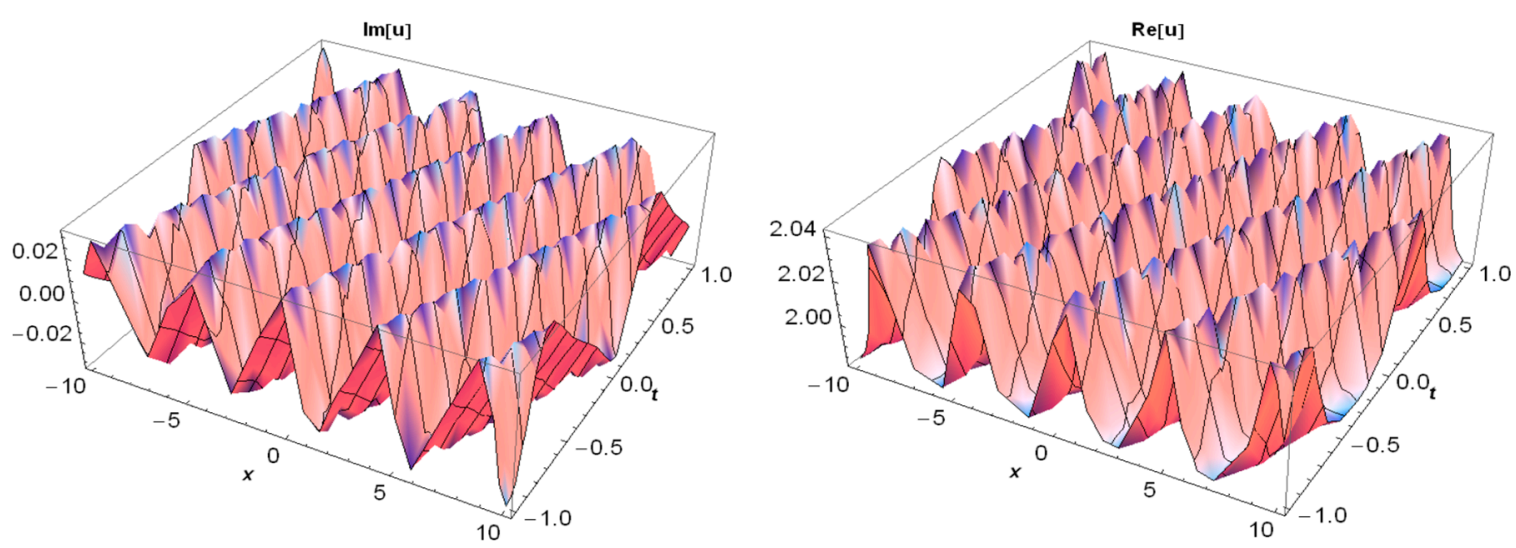

Figure 16. 3D surfaces of Equation (28). 

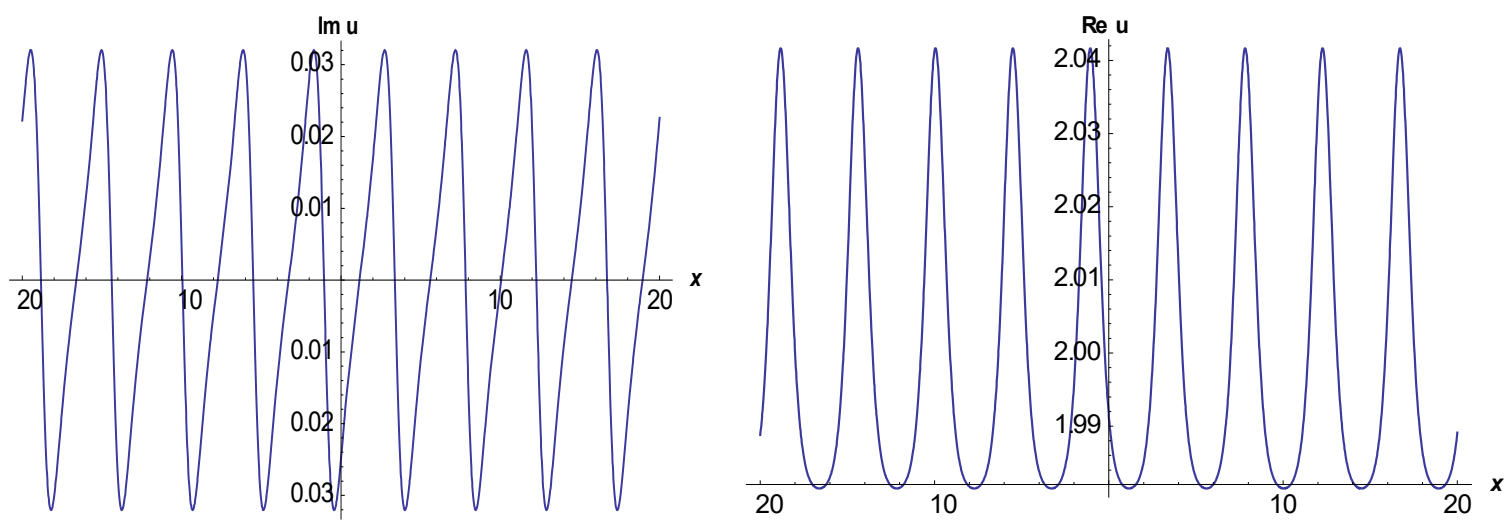

Figure 17. 2D surfaces of Equation (28).
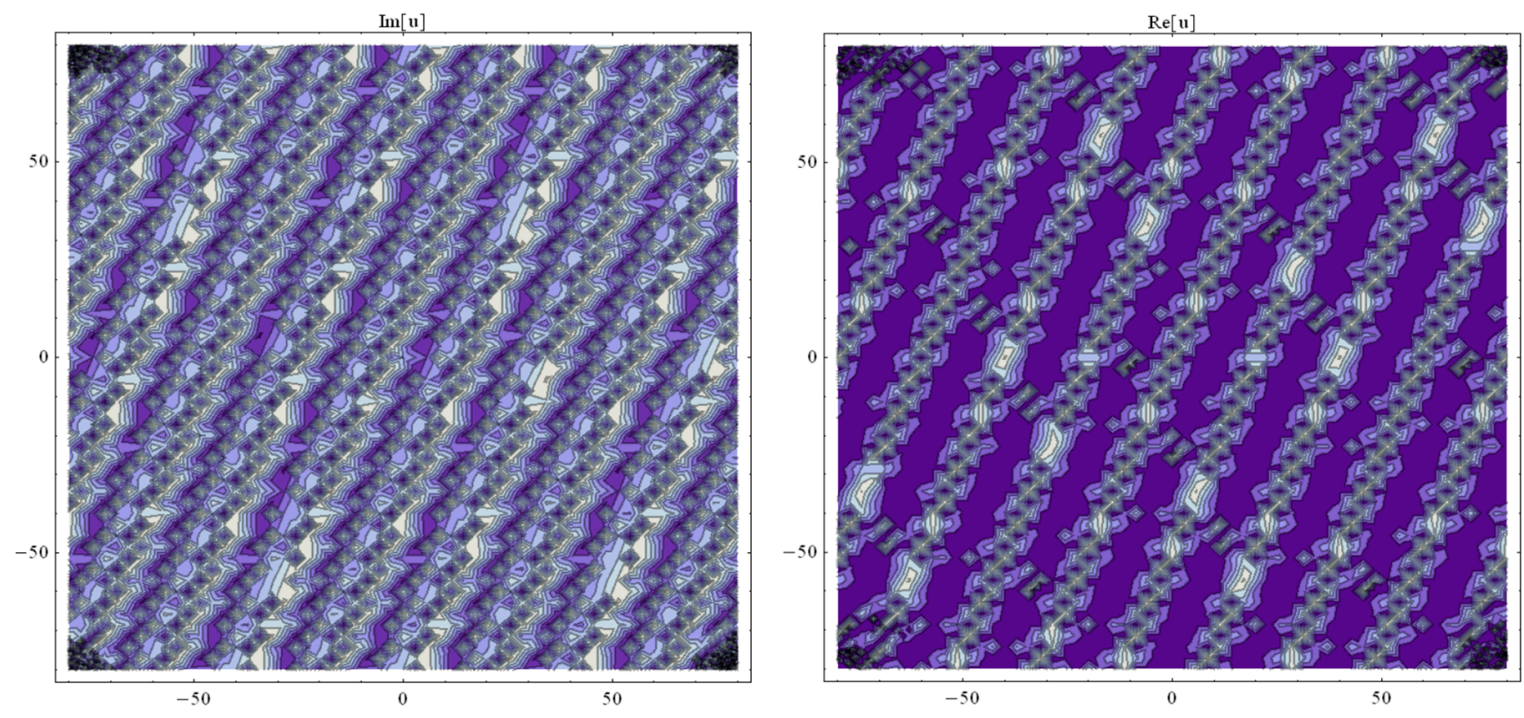

Figure 18. Contour simulations of Equation (28).

\section{Conclusions}

This manuscript presents a set of complex soliton solutions to the GPE with the help of BSEFM. New complex soliton solutions, such as exponential, rational, and the complex exponential are obtained. To give better understanding of the physical importance of the solutions found in this paper, the process of choosing the suitable values for the parameters is shown, and the three- and two-dimensional graphs and contour simulations of the these solutions are drawn. The alternative points of view to the solutions (i.e., Equations (16), (18), (20), (22), (26), and (28)) can be seen in the 3D and 2D graphs in Figures 1, 2, 4, 7, 10, 13 and 16, Figure 5, Figure 8, Figure 11, Figure 14, Figure 17, respectively. The contour patterns on which the wave propagates along the $\mathrm{x}$-axis for complex solutions obtained in this paper can be also viewed from Figure 3, Figure 6, Figure 9, Figure 12, Figure 15, Figure 18, separately as imaginary and real parts of the solutions. The contour surfaces are another and new alternative simulation to the $3 \mathrm{D}$ graph, giving more detailed information in terms of physical properties of the constructed solutions. Comparing such results, produced in this manuscript, with the papers which have been published in [1,4], it can be seen that these complex soliton solutions are entirely new for the GPE. The calculations show that this method is a reliable and efficient scheme which yields many complex results to the other nonlinear partial differential equations.

Funding: This research received no external funding.

Conflicts of Interest: The authors declare no conflict of interest. 


\section{References}

1. Gilson, C.; Pickering, A. Factorization and Painleve analysis of a class of nonlinear third-order partial differential equations. J. Phys. A Math. Gen. 1995, 28, 2871-2888. [CrossRef]

2. Irshad, A.; Mohyud-Din, S.T. Tanh-Coth Method for Nonlinear Differential Equations. Stud. Nonlinear Sci. 2012, 3, 24-48.

3. Fan, X.; Yang, S.; Zhao, D. Travelling wave solutions for the Gilson-Pickering equation by using the simplified G'/G-expansion method. Int. J. Nonlinear Sci. 2009, 8, 368-373.

4. Ebadia, G.; Karab, A.H.; Petkovic, M.D.; Biswas, A. Soliton solutions and conservation laws of the Gilson-Pickering equation. Waves Random Complex Media 2011, 21, 378-385. [CrossRef]

5. Chen, A.; Huang, W.; Tang, S. Bifurcations of travelling wave solutions for the Gilson-Pickering equation. Nonlinear Anal. Real World Appl. 2009, 10, 2659-2665. [CrossRef]

6. Ebadi, G.; Biswas, A. Application of the $\mathrm{G}^{\prime} / \mathrm{G}-$ Expansion method for nonlinear diffusion equations with nonlinear source. J. Frankl. Inst. 2010, 347, 1391-1398. [CrossRef]

7. Li, C.; Tang, S.; Huang, W.; Chen, A. Peakons, Solitary Patterns and Periodic Solutions for Generalized Gilson-Pickering Equations. Far East J. Appl. Math. 2009, 35, 301-307.

8. Zabihi, F.; Saffarian, M. A Meshless Method Using the Radial Basis Functions for Numerical Solution of the Gilson-Pickering Equation. In Proceedings of the 46th Annual Iranian Mathematics Conference, Yazd, Iran, 25-28 August 2015; pp. 1-4.

9. Aslan, I. Exact and explicit solutions to nonlinear evolution equations using the division theorem. Appl. Math. Comput. 2011, 217, 8134-8139. [CrossRef]

10. Araci, S.; Ozer, O. Extended q-Dedekind-type Daehee-Changhee sums associated with extended q-Euler polynomials. Adv. Differ. Equ. 2015, 2015, 272-276. [CrossRef]

11. Cattani, C.; Sulaiman, T.A.; Baskonus, H.M.; Bulut, H. On the soliton solutions to the Nizhnik-Novikov-Veselov and the Drinfel'd-Sokolov systems. Opt. Quantum Electron. 2018, 50, 138. [CrossRef]

12. Cattani, C.; Sulaiman, T.A.; Baskonus, H.M.; Bulut, H. Solitons in an inhomogeneous Murnaghan's rod. Eur. Phys. J. Plus 2018, 133, 228. [CrossRef]

13. Cattani, C.; Ciancio, A. On the fractal distribution of primes and prime-indexed primes by the binary image analysis. Phys. A 2016, 460, 222-229. [CrossRef]

14. Sulaiman, T.A.; Bulut, H.; Yokus, A.; Baskonus, H.M. On the exact and numerical solutions to the coupled Boussinesq equation arising in ocean engineering. Indian J. Phys. 2018, 1-10, Accepted. [CrossRef]

15. Ciancio, A.; Baskonus, H.M.; Sulaiman, T.A.; Bulut, H. New structural dynamics of isolated waves via the coupled nonlinear Maccari's system with complex structure. Indian J. Phys. 2018, 92, 1281-1290. [CrossRef]

16. Baskonus, H.M. New complex and hyperbolic function solutions to the generalized double combined Sinh-Cosh-Gordon equation. In AIP Conference Proceedings; AIP Publishing: Melville, NY, USA, 2017; Volume 1798, p. 020018.

17. Ciancio, A.; Quartarone, A. A Hybrid Model for Tumor-Immune Competition. U.P.B. Sci. Bull. Series A 2013, 75, 125-136.

18. Baskonus, H.M. New acoustic wave behaviors to the Davey-Stewartson equation with power-law nonlinearity arising in fluid dynamics. Nonlinear Dyn. 2016, 86, 177-183. [CrossRef]

19. Seadawy, A. Three-dimensional nonlinear modified Zakharov-Kuznetsov equation of ion-acoustic waves in a magnetized plasma. Comput. Math. Appl. 2016, 71, 201-206. [CrossRef]

20. Ünlükal, C.; Şenel, M.; Şenel, B. Risk Assessment with Failure Mode and Effect Analysis and Gray Relational Analysis Method in Plastic Enjection Prosess. In Proceedings of the ITM Web of Conference, Girne, Cyprus, 4-6 May 2018; Volume 22, pp. 1-10.

21. Bulut, H.; Sulaiman, T.A.; Baskonus, H.M.; Yazgan, T. Novel Hyperbolic Behaviors to Some Important Models Arising in Quantum Science. Opt. Quantrum. Electron. 2017, 49, 349. [CrossRef]

22. Sulaiman, T.A.; Yokus, A.; Gulluoglu, N.; Baskonus, H.M.; Bulut, H. Regarding the Numerical and Stability Analysis of the Sharma-Tosso-Olver Equation. In Proceedings of the ITM Web of Conference, Girne, Cyprus, 4-6 May 2018; Volume 22, pp. 1-9.

23. Ilhan, O.A.; Sulaiman, T.A.; Bulut, H.; Baskonus, H.M. On the new wave Solutions to a Nonlinear Model Arising in Plasma Physics. Eur. Phys. J. Plus. 2018, 133, 27. [CrossRef] 
24. Ozer, O. A Note on Structure of Certain Real Quadratic Number Fields. Iran. J. Sci. Technol. 2017, 41, 759-769. [CrossRef]

25. Baskonus, H.M.; Sulaiman, T.A.; Bulut, H.; Akturk, T. Investigations of dark, bright, combined dark-bright optical and other soliton solutions in the complex cubic nonlinear Schrödinger equation with-potential. Superlattices Microstruct. 2018, 115, 19-29. [CrossRef]

26. Yokus, A.; Sulaiman, T.A.; Gulluoglu, M.T.; Bulut, H. Stability Analysis, Numerical and Exact Solutions of the (1+1)-Dimensional NDMBBM Equation. In Proceedings of the ITM Web of Conference, Girne, Cyprus, 4-6 May 2018; Volume 22, pp. 1-10.

27. Yokus, A.; Sulaiman, T.A.; Baskonus, H.M.; Atmaca, S.P. On the exact and numerical solutions to a nonlinear model arising in mathematical biology. In Proceedings of the ITM Web of Conference, Girne, Cyprus, 4-6 May 2018; Volume 22, pp. 1-10.

28. Baskonus, H.M.; Askin, M. Travelling Wave Simulations to the Modified Zakharov-Kuznetsov Model Arising in Plasma Physics. In Proceedings of the 6th International Youth Science Forum LITTERIS ET ARTIBUS, Computer Science and Engineering, Lviv, Ukraine, 24-26 November 2016.

29. Cilingir, I.; Demir, H. Application of the Hybrid Differential Transform Method to the nonlinear equations. Appl. Math. 2012, 3, 1-10.

30. Cattani, C. A review on Harmonic Wavelets and their fractional extension. J. Adv. Eng. Comput. 2018, 2, 224-238. [CrossRef]

31. Cilingir, I.; Demir, H. New Algorithm for the Lid-driven Cavity Flow Problem with Boussinesq-Stokes Suspension. Karaelmas J. Sci. Eng. 2018, 8, 462-472.

32. Arshad, M.; Seadawy, A.R.; Lu, D. Bright-dark solitary wave solutions of generalized higher-order nonlinear Schrödinger equation and its applications in optics. J. Electromagn. Waves Appl. 2017, 31, 1711-1721. [CrossRef]

33. Demir, H. Temporal differential transform and spatial finite difference methods for unsteady heat conduction equations with anisotropic diffusivity. Gazi Univ. J. Sci. 2014, 27, 1063-1076.

34. Seadawy, A.R. Ionic acoustic solitary wave solutions of two-dimensional nonlinear Kadomtsev-Petviashvili-Burgers equations in quantum plasma. Math. Methods Appl. Sci. 2017, 40, 1598-1607. [CrossRef]

35. Lu, D.; Seadawy, A.R.; Khater, M.M. Bifurcations of new multi soliton solutions of the van der Waals normal form for fluidized granular matter via six different methods. Results Phys. 2017, 7, 2028-2035. [CrossRef]

36. Seadawy, A.R.; Lu, D.; Khater, M.M. Bifurcations of traveling wave solutions for Dodd-Bullough-Mikhailov equation and coupled Higgs equation and their applications. Chin. J. Phys. 2017, 55, 1310-1318. [CrossRef]

37. Ozer, O. Determination of Fundamental Units of Real Quadratic Number Fields Related with Specific Continued Fraction Expansions. Egypt. Comput. Sci. J. 2018, 42, 1-12.

38. Ozer, O.; Pekin, A. An Algorithm for Explicit Form of Fundamental Units of Certain Real Quadratic Fields and Period Eight. Eur. J. Pure Appl. Math. 2015, 8, 343-356.

39. Bas, E.; Panakhov, E.; Yilmazer, R. The uniqueness theorem for hydrogen atom equation. TWMS J. Pure Appl. Math. 2013, 4, 20-28.

40. Duran, S.; Askin, M.; Sulaiman, T.A. New soliton properties to the ill-posed Boussinesq equation arising in nonlinear physical science. Int. J. Optim. Control Theor. Appl. 2017, 7, 240-247. [CrossRef]

41. Askin, M. Effect of the Transition Metal Elements on the Relaxation Times in the Agar Solutions. Asian J. Chem. 2007, 19, 3191-3196.

42. Baskonus, H.M.; Koc, D.A.; Bulut, H. New travelling wave prototypes to the nonlinear Zakharov-Kuznetsov equation with power law nonlinearity. Nonlinear Sci. Lett. A Math. Phys. Mech. 2016, 7, 67-76.

43. Bulut, H.; Atas, S.S.; Baskonus, H.M. Some novel exponential function structures to the Cahn-Allen equation. Cogent Phys. 2016, 3, 1-8. [CrossRef]

44. Baskonus, H.M.; Erdogan, F.; Ozkul, A.; Asmouh, I. Novel Behaviors to the Nonlinear Evolution Equation Describing the Dynamics of Ionic Currents along Microtubules. In Proceedings of the ITM Web of Conference, Istanbul, Turkey, 20-22 May 2017; Volume 13, pp. 1-5.

45. Zheng, B. Application of a Generalized Bernoulli SubODE Method for Finding Traveling Solutions of Some Nonlinear Equations. WSEAS Trans. Math. 2012, 7, 618-626. 
46. Baskonus, H.M.; Bulut, H.; Emir, D.G. Regarding New Complex Analytical Solutions for the Nonlinear Partial Vakhnenko-Parkes Differential Equation via Bernoulli Sub-Equation Function Method. Math. Lett. 2015, 1, 1-9.

47. Ma, W.X.; Fuchssteiner, B. Explicit and Exact Solutions to a Kolmogorov-Petrovskii-Piskunov Equation. Int. J. Non-Linear Mech. 1996, 31, 329-338. [CrossRef]

48. Ma, W.X.; Li, J.; Khalique, C.M. A Study on Lump Solutions to a Generalized Hirota-Satsuma-Ito Equation in (2+1)-Dimensions. Complexity 2018, 2018. [CrossRef]

49. Yang, J.Y.; Ma, W.X.; Qin, Z. Abundant Mixed Lump-Soliton Solutions to the BKP Equation. East Asian J. Appl. Math. 2018, 8, 224-232. [CrossRef]

50. Yang, J.Y.; Ma, W.X.; Qin, Z. Lump and lump-soliton solutions to the (2+1)-Dimensional Ito equation. Anal. Math. Phys. 2018, 8, 427-436. [CrossRef]

(c) 2019 by the author. Licensee MDPI, Basel, Switzerland. This article is an open access article distributed under the terms and conditions of the Creative Commons Attribution (CC BY) license (http://creativecommons.org/licenses/by/4.0/). 